\title{
Transcriptomic study of dormant gastrointestinal cancer stem cells
}

\author{
SHIMPEI NISHIKAWA ${ }^{1,2}$, DYAH LAKSMI DEWI ${ }^{1,2}$, HIDESHI ISHII $^{1}$, MASAMITSU KONNO $^{1}$, \\ NAOTSUGU HARAGUCHI ${ }^{1}$, YOSHIHIRO KANO ${ }^{1,2}$, TAKAHITO FUKUSUMI ${ }^{1,2}$, \\ KATSUYA OHTA $^{1,2}$, YUKO NOGUCHI ${ }^{1,2}$, MIYUKI OZAKI ${ }^{1,2}$, DAISUKE SAKAI ${ }^{1}$, \\ TAROH SATOH $^{1}$, YUICHIRO DOKI ${ }^{2}$ and MASAKI MORI ${ }^{2}$ \\ Departments of ${ }^{1}$ Frontier Science for Cancer and Chemotherapy and ${ }^{2}$ Gastroenterological Surgery, \\ Osaka University, Graduate School of Medicine, Suita, Osaka 565-0871, Japan
}

Received March 5, 2012; Accepted May 16, 2012

DOI: $10.3892 /$ ijo.2012.1531

\begin{abstract}
We previously discovered the coexistence of dormant and proliferating cancer stem cells (CSCs) in gastrointestinal cancer, which leads to chemoradiation resistance. $\mathrm{CD} 13^{-} / \mathrm{CD} 90^{+}$ proliferating liver CSCs are sensitive to chemotherapy, and $\mathrm{CD}^{3} 3^{+} / \mathrm{CD} 90^{-}$dormant $\mathrm{CSC}$ s have a limited proliferation ability, survive in hypoxic areas with reduced oxidative stress, and relapse and metastasize to other organs. In such $\mathrm{CD}_{1}{ }^{+}$dormant cells, non-homologous end-joining, an error-prone repair mechanism, is dominant after DNA damage, whereas high-fidelity homologous recombination is apparent in $\mathrm{CD}^{-} 3^{-}$proliferating cells, suggesting the significance of dormancy as an essential protective mechanism of therapy resistance. However, this mechanism may also play a role in the generation and accumulation of heterogeneity during cancer progression, although the exact mechanism remains to be understood. Through transcriptomic study, we elucidated the underlying epigenetic mechanism for malignant behavior of dormant CSCs, i.e., simultaneous activation of several pathways including EZH2- and TP53related proteins in response to microRNA101, suggesting that a pharmacogenomic approach would open an era to novel molecular targeting cancer therapy.
\end{abstract}

\section{Introduction}

Recent studies have revealed that cancer stem cells (CSCs) are a source of therapy resistance, disease recurrence, and metastasis to other organs (1-3). At least two types of CSCs, dormant (dCSC) and activated (aCSC), are involved in tumor homeostasis, which are in contrast to two types of stem cells,

Correspondence to: Dr Masaki Mori, Department of Gastroenterological Surgery, Osaka University, Graduate School of Medicine, Suita, Yamadaoka 2-2, Osaka 565-0871, Japan

E-mail: mmori@gesurg.med.osaka-u.ac.jp

Professor Hideshi Ishii, Department of Frontier Science for Cancer and Chemotherapy, Osaka University, Graduate School of Medicine, Suita, Yamadaoka 2-2, Osaka 565-0871, Japan

E-mail: hishii@cfs.med.osaka-u.ac.jp

Key words: transcriptome, cancer stem cells, dormancy, chemotherapy dormant and activated types in normal skin, intestine and the hematopoietic system (4). Our previous study indicated that $\mathrm{CD}_{13}{ }^{+} \mathrm{CD} 90^{-} \mathrm{dCSC}$ of hepatocellular carcinoma survive in hypoxic areas in marginal regions in liver after therapy (5). In $\mathrm{CD}_{13}{ }^{+} / \mathrm{CD} 90^{-} \mathrm{dCSCs}$, the occurrence of double-strand breaks (DSBs) in genomic DNA, a deleterious cellular event, and damage-induced repairs that are necessary for cellular survival (6), reduce after therapy presumably due to CD13/ aminopeptidase $\mathrm{N}$ functioning as a scavenger of reactive oxygen species (ROS) (5) and partially due to error-prone repair such as non-homologous end-joining (NHEJ) $(6,7)$. In a sharp contrast, $\mathrm{CD}^{2} / \mathrm{CD}^{-} 0^{+} \mathrm{dCSC}$ are sensitive to therapeutic insults from chemotherapeutic agents, which is associated with ROS-induced cell death after chemotherapy (8); however, damage is typically repaired though high-fidelity, error-free homologous recombination (HR) (6,7). Thus, dCSCs may be a cause of accumulation of deleterious mutations and should be targeted in therapy in terms of complete eradication of malignant cells, although hibernation therapy (the induction of dormancy) may be a viable option dependent on the patient's condition (7). Chemotherapy results in a shift from aCSCs to dCSCs and accumulation of dCSCs after treatment, and dormancy may function as a type of refuge for the survival of malignant cells. CD13 cells play a role in the inhibition of increase in ROS and the resultant suppression of cell death during the process of epithelial mesenchymal transition (EMT) of metastatic CSCs (9). The exposure to a CSC-specific inhibitor, ubenimex, resulted in considerable eradication of malignant cells in vivo, indicating an apparent benefit in the combination of conventional chemotherapy and a CSC-specific inhibitor.

Here, we performed transcriptome analysis for coding mRNAs and non-coding microRNAs (miRs) in $\mathrm{CD}^{+} 3^{+} \mathrm{CD} 90^{-}$ dCSCs. This study allowed us to identify several pathways, which play a role in fundamental mechanisms in abovementioned potentially malignant phenotype, and provided further clues for identification of molecular targets in therapeutic approaches for dCSCs.

\section{Materials and methods}

Cell cultures. Cell lines were maintained in Dulbecco's modified Eagle's medium (DMEM; Nacalai Tesque, Kyoto, Japan) 

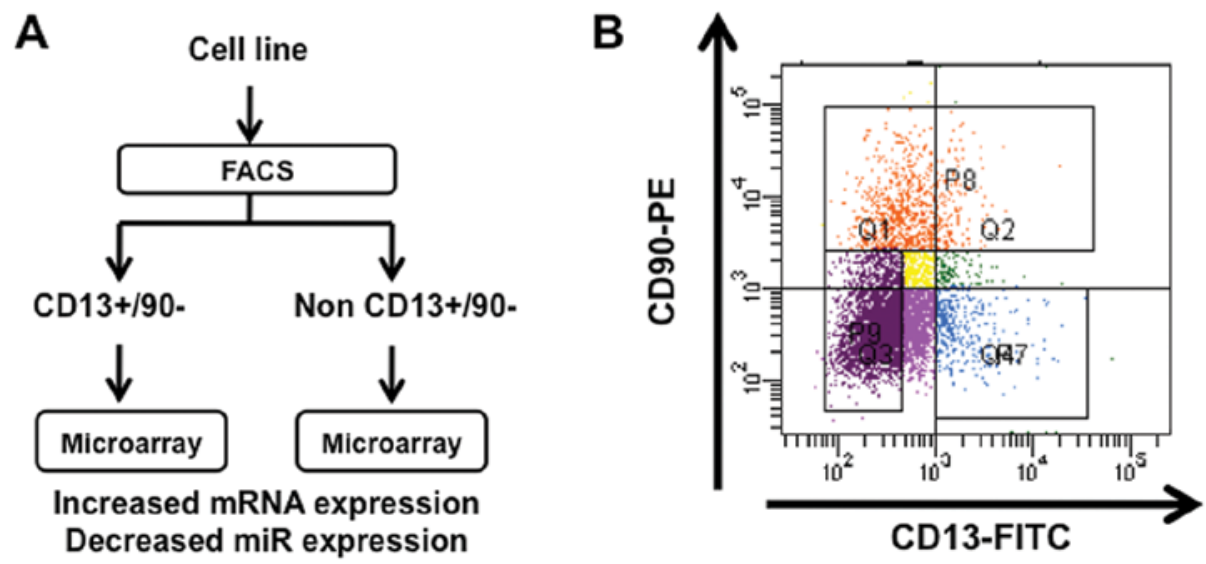

Figure 1. Isolation and analysis of liver dCSCs. (A) Cells were separated by FACS into dCSCs $\left(\mathrm{CD}^{+} 3^{+} / \mathrm{CD} 90^{-}\right)$and non-dCSCs $\left(\mathrm{CD} 13^{+} / \mathrm{CD} 90^{+}\right.$, CD13 $/ \mathrm{CD} 90^{+}$, and $\left.\mathrm{CD} 13^{-} / \mathrm{CD} 90^{-}\right)$. Total-RNA was extracted and subjected to array screening for mRNA and miR. Here we focused on increased mRNA expression and decreased miR expression. (B) Representative data of FACS separation and sorting.

supplemented with $10 \%$ fetal bovine serum (FBS) at $37^{\circ} \mathrm{C}$ in a $5 \%$ humidified $\mathrm{CO}_{2}$ atmosphere.

Flow cytometric analysis and cell sorting. The antibodies used were purchased from BD Biosciences (Tokyo, Japan). In brief, cells were harvested with trypsin and EDTA. Doublet cells were eliminated using FSC-A/FSC-H and SSC-A/SSC-H. Dead and dying cells were eliminated with 7-AAD (BD Pharmingen, San Jose, CA, USA). Isotype controls (BD Biosciences) were used. FcR blocking was performed using an FcR blocking reagent (Miltenyi Biotec, Bergisch Gladbach, Germany).

$R N A$. Total-RNA was extracted using TRIzol reagent (Invitrogen/Life Technologies Japan, Tokyo, Japan). Reverse transcription was performed with SuperScript III reverse transcription kit (Invitrogen). qPCR was performed using the LightCycler TaqMan Master Kit (Roche Diagnostics, Tokyo, Japan) for cDNA amplification of target-specific genes. Purified cDNA from mouse ES cells was used as a positive control for target genes. The expression of mRNA copies was normalized to GAPDH (for mRNA) or RNU48 (for miR) expression, as indicated. The RNA samples were analyzed using SurePrint G3 Human GE 8x60K Microarray and the Human miRNA Microarray 8x15K Rel.12.0 (Takara, Kyoto, Japan).

Statistical analysis. For continuous variables, results are expressed as means $\pm \mathrm{SE}$. The relationship between the gene expression level and cell count was analyzed by chi-square and Wilcoxon rank tests. All data were analyzed using JMP software (SAS Institute, Cary, NC, USA). P-values of $<0.05$ were considered statistically significant.

\section{Results and Discussion}

A study of $\mathrm{CD}^{+} 3^{+} / \mathrm{CD} 90^{-}$as $d C S C$ s. $\mathrm{CD}^{+} 3^{+} /$aminopeptidase $\mathrm{N}$ is expressed in liver CSCs (5), where it is involved in the reduction of ROS through the glutathione reductase pathway. Considering that another independent study has shown $\mathrm{CD} 90^{+}$ as a candidate stem marker, critical to tumorigenicity in mice in vivo and clinical outcomes of patients (10), we indicated that $\mathrm{CD} 13^{+} / \mathrm{CD} 90^{-}$cells exist in dormant phase of cell cycle, whereas $\mathrm{CD} 13^{+} / \mathrm{CD} 90^{+}$cells are predominantly in the $\mathrm{S}$ phase and $\mathrm{CD} 13^{-} / \mathrm{CD} 90^{+}$cells are in the $\mathrm{G} 2 / \mathrm{M}$ phase (5). In previous studies, we have elucidated that following exposure to genotoxic insults, such as chemotherapy or radiation therapy, CD13 cells shift to the $\mathrm{CD}^{-} 3^{+}$fraction in dormant phase of cell cycle. In dCSCs, double stranded breaks (DSBs) are repaired predominantly through the error-prone NHEJ mechanism $(6,7)$. In sharp contrast, the high-fidelity HR-type repair proteins are increased in non-dormant CSCs compared with NHEJ proteins, of which cells are usually sensitized through chemoradiation therapy $(6,7)$. Thus, after chemoradiation therapy, NHEJ supposedly contributes to the generation of misrepair after DSBs, which may cause chromosomal deletions, insertions, or translocations, and subsequent genomic instability (11). Such genomic alterations lead to the inactivation of tumor suppressor genes and activation of oncogenes, which become more apparent during tumor development of primary lesions, recurrence and metastasis (12). Nevertheless, there remains an important issue to be addressed, i.e., the identification of molecular mechanisms fundamental for initiation and development of tumor tissues composed of stem cell hierarchy, and moreover, the type of mechanism involved in CSC-based heterogeneous tumors. We began with transcriptome assessment, i.e., the expression of mRNAs and miRs and their association with $\mathrm{CD} 13^{+} / \mathrm{CD} 90^{-}$cells in supporting or maintaining CSC survival in the absence of genotoxic stimuli, which may be beneficial in the study of the basal situation and may help understand the differences between therapy-resistant clones and de novo tumor-initiating cells.

As shown in Fig. 1, we separated liver cancer cells by FACS sorting into $\mathrm{CD} 13^{+} \mathrm{CD} 90^{-} \mathrm{dCSC}$ from other nonCSCs. Considering that miRs play a role in the regulation of mRNA in its stability and translation as an inhibitory regulation system, we focused on increased expression of mRNA clones and decreased expression of miR clones. The data of high-density array screening indicated 17 clones of increased expression in $\mathrm{CD}^{+} 3^{+} \mathrm{CD} 90^{-}$populations compared with unsorted cells with more than 2-fold significant increase. The data were almost consistent in $\mathrm{CD} 13^{+} / \mathrm{CD} 90^{-}$populations 
Table I. mRNAs expressed highly in CD13+CD90- PLC cells.

\begin{tabular}{|c|c|c|}
\hline mRNA & $\begin{array}{c}\mathrm{CD} 13^{+} \mathrm{CD} 90^{-} / \\
\text {unsorted }\end{array}$ & $\begin{array}{c}\mathrm{CD} 13^{+} \mathrm{CD} 90^{-} / \\
\text {non-CD } 13^{+} \mathrm{CD} 90\end{array}$ \\
\hline Cadherin 6, type 2, K-cadherin (CDH6) & 3.33 & 3.21 \\
\hline Interleukin 8 (IL8) & 3.27 & 1.50 \\
\hline Aldehyde dehydrogenase 1 family, member A3 (ALDH1A3) & 3.26 & 2.61 \\
\hline Endothelin 1 (EDN1) & 3.20 & 1.16 \\
\hline Cytochrome P450, family 1, subfamily B, polypeptide 1 (CYP1B1) & 3.16 & 2.06 \\
\hline Tumor necrosis factor, $\alpha$-induced protein 6 (TNFAIP6) & 3.13 & 1.83 \\
\hline Chemokine (C-X-C motif) ligand 1 (CXCL1) & 3.08 & 1.25 \\
\hline Vascular cell adhesion molecule 1 (VCAM1) & 2.94 & 2.49 \\
\hline L1 cell adhesion molecule (L1CAM) & 2.72 & 2.40 \\
\hline Wingless-type MMTV integration site family member 2 (WNT2) & 2.66 & 1.10 \\
\hline Carcinoembryonic antigen-related cell adhesion molecule 3 (CEACAM3) & 2.65 & 1.99 \\
\hline Chemokine (C-X-C motif) ligand 3 (CXCL3) & 2.29 & 1.79 \\
\hline Chemokine (C-C motif) ligand 20 (CCL20) & 2.24 & 2.44 \\
\hline Chemokine (C-X-C motif) ligand 12 (CXCL12) & 2.11 & 1.53 \\
\hline Tumor necrosis factor (TNF superfamily, member 2) (TNF) & 2.07 & 1.59 \\
\hline Chemokine (C-X-C motif) ligand 5 (CXCL5) & 2.04 & 1.52 \\
\hline Wingless-type MMTV integration site family, member 7B (WNT7B) & 2.02 & 1.16 \\
\hline
\end{tabular}

The relative expressions in $\mathrm{CD} 13^{+} \mathrm{CD} 90^{-} \mathrm{PLC}$ cells are shown as the ratio to unsorted, or to excluded populations (non $\mathrm{CD}_{13}^{+} \mathrm{CD} 90^{-}$).

Table II. miRs expressed highly in $\mathrm{CD}^{+} 3^{+} \mathrm{CD} 90^{-} \mathrm{PLC}$ cells.

\begin{tabular}{|c|c|c|c|}
\hline $\operatorname{miR}$ & $\begin{array}{l}\mathrm{CD}^{2} 3^{+} \mathrm{CD} 90^{-} / \\
\text {unsorted }\end{array}$ & $\begin{array}{l}\text { Non } \mathrm{CD} 13^{+} \mathrm{CD} 90^{-} / \\
\text {unsorted }\end{array}$ & Function \\
\hline hsa-miR-374a & -8.24 & 0.19 & Downregulated upon cisplatin exposure \\
\hline hsa-miR-489 & -7.17 & 0.41 & $\begin{array}{l}\text { miR-489 inhibited cell growth in all head } \\
\text { and neck cancer cell lines }\end{array}$ \\
\hline hsa-miR-223 & -6.69 & 0.16 & $\begin{array}{l}\text { Reduced miR-223 expression in primary MEF leads to } \\
\text { increased Fbw } 7 \text { expression and decreased cyclin-E activity }\end{array}$ \\
\hline hsa-miR-101 & -6.68 & -0.21 & $\begin{array}{l}\text { miR-101 could sensitize hepatoma cell lines to both } \\
\text { serum starvation- and chemotherapeutic drug-induced } \\
\text { apoptosis. Genomic loss of miR } 101 \text { leads to overexpression } \\
\text { of histone methyltransferase EZH2 in cancer }\end{array}$ \\
\hline hsa-miR-9 & -6.29 & 0.70 & Directly repress Lin 28 \\
\hline hsa-miR-378 & -6.21 & -0.06 & $\begin{array}{l}\text { Novel target of the c-Myc oncoprotein that is able } \\
\text { to cooperate with activated Ras or HER } 2 \text { to promote } \\
\text { cellular transformation }\end{array}$ \\
\hline hsa-miR-182 & -6.14 & -0.68 & $\begin{array}{l}\text { Antagonizing miR-182 enhances BRCA1 protein levels } \\
\text { and protects them from IR-induced cell death }\end{array}$ \\
\hline hsa-miR-421 & -5.69 & 0.20 & $\begin{array}{l}\text { Overexpression of miR- } 421 \text { in pancreatic cancer cells } \\
\text { promoted cell proliferation and colony formation }\end{array}$ \\
\hline hsa-miR-125a-3p & -4.99 & 0.01 & Hypoxia regulated microRNA \\
\hline
\end{tabular}

The relative expressions in $\mathrm{CD} 13^{+} \mathrm{CD} 90^{-}$PLC cells are shown as the ratio to unsorted, or to excluded populations (non $\mathrm{CD} 13^{+} \mathrm{CD} 90^{-}$).

compared with non-CD $13^{+} / \mathrm{CD} 90^{-}$cells (Table I). Next, we analyzed miR expression and successfully isolated nine miRs in $\mathrm{CD}_{13}{ }^{+} / \mathrm{CD} 90^{-}$population compared with unsorted cells with more than 4-fold significant decrease. The data were almost consistent in $\mathrm{CD}^{+} / 3^{+} \mathrm{CD} 90^{-}$populations compared with non-CD13 ${ }^{+} / \mathrm{CD}^{-} 0^{-}$cells (Table II). 

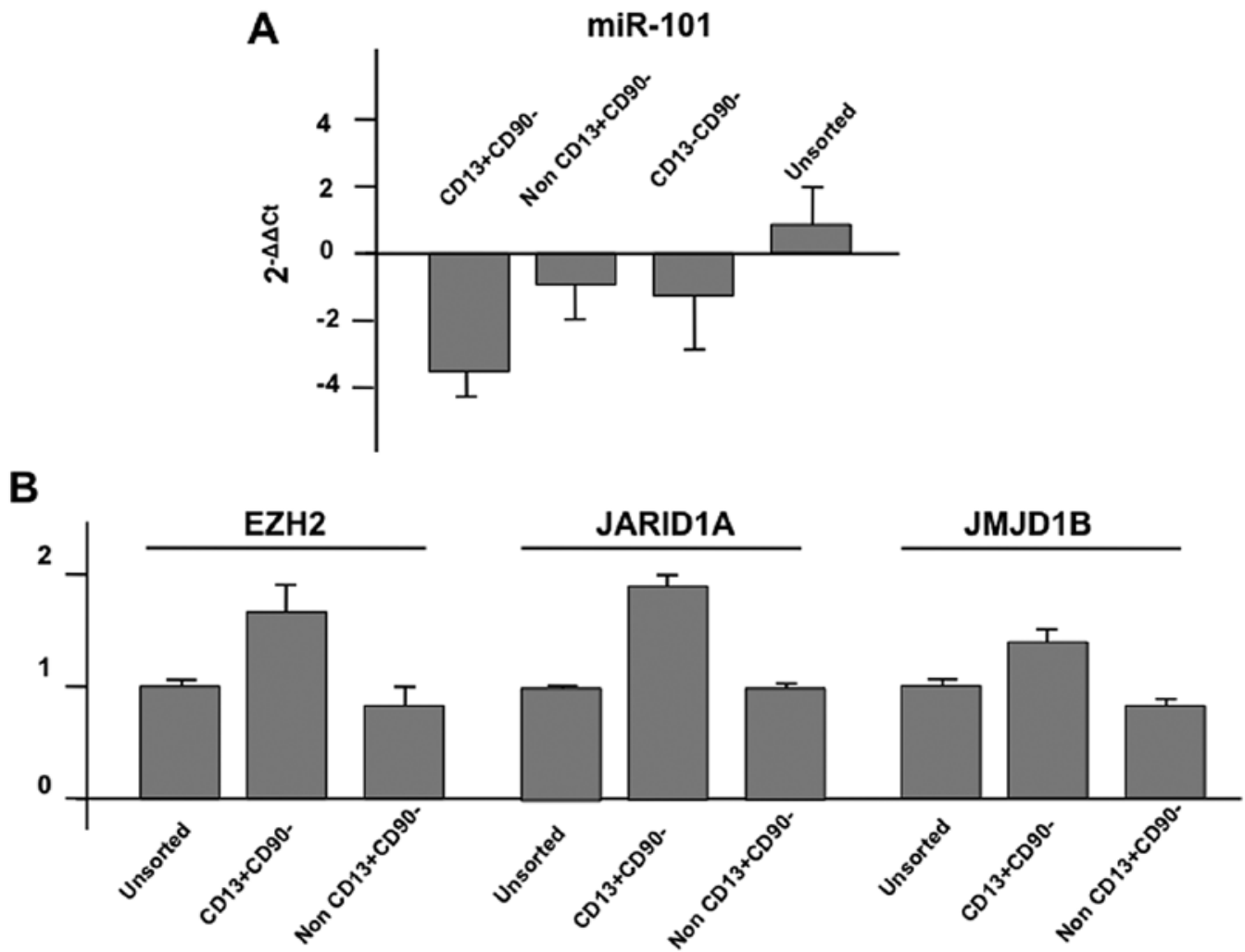

Figure 2. Quantitative analysis of isolated mRNA and miR transcripts by RT-PCR. RNAs from cells were extracted and subjected to qRT-PCR. Data of (A) miR study and (B) mRNA study are shown.

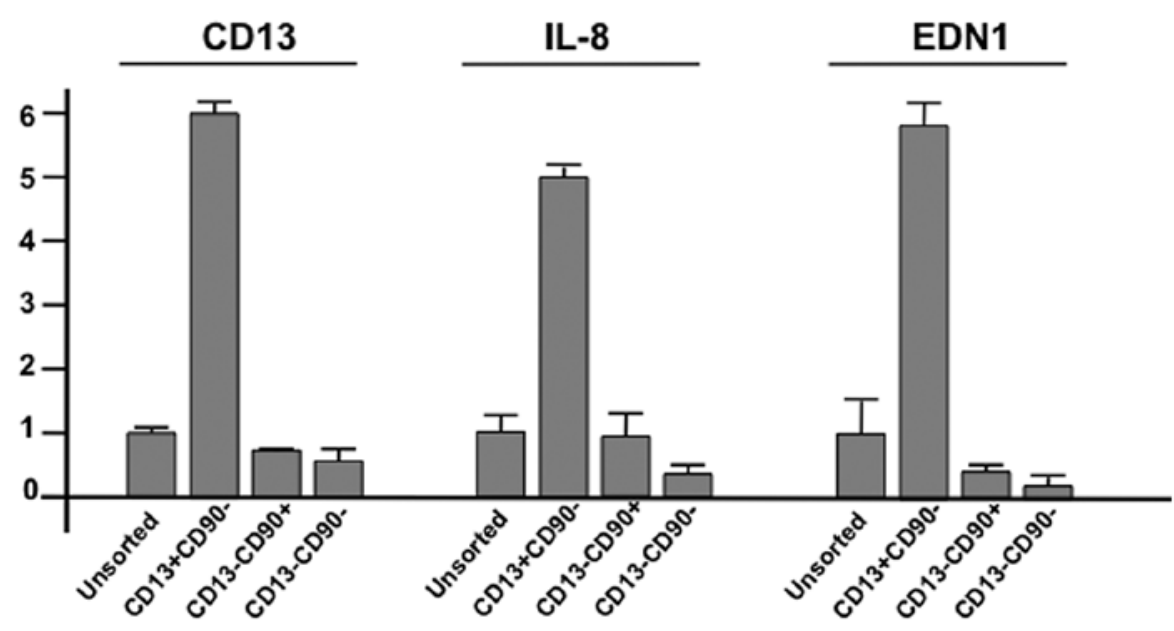

Figure 3. Quantitative analysis of isolated mRNA and miR transcripts by RT-PCR. RNAs from cells were extracted and subjected to qRT-PCR. Data of mRNA study are shown.

Identification of regulatory networks. By assessment of pairs of miRs and its putative target mRNAs using prediction software (http://www.targetscan.org/; http://www.microrna.org/ microrna/home.do), we confirmed the data of the array by quantitative PCR. As shown in the representative data, the expression of miR-101 was downregulated in $\mathrm{CD}^{+} 3^{+} \mathrm{CD}^{-} 0^{-}$ cells compared with non-CD13 ${ }^{+}$CD $90^{-}$cells or $\mathrm{CD} 13 \%$ CD90- cells; in sharp contrast, the expression of putative targets, EZH2 (enhancer of zeste homolog 2; http://www. genecards.org/cgi-bin/carddisp.pl?gene=EZH2\&search $=$
EZH2), JARID1A; (http://www.genecards.org/cgi-bin/carddisp.pl?gene $=$ KDM5A\&search=JARID1A), and JMJD1B (http://www.genecards.org/cgi-bin/carddisp.pl?gene=KDM3B\& search=JMJD1B) were increased (Fig. 2; summarized in Fig. 3). CD13 mRNA expression was increased in $\mathrm{CD}^{+} 3^{+} / \mathrm{CD}^{-} 0^{-}$cells,

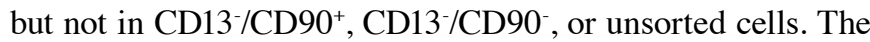
expression of interleukin-8 (IL-8; http://www.genecards.org/ cgi-bin/carddisp.pl?gene $=$ IL8\&search=Interleukin +8$)$ and endothelin 1 (EDN1; http://www.genecards.org/cgi-bin/carddisp.pl?gene $=$ EDN1\&search $=$ Endothelin +1$)$ was increased in 
A miR-182 Pathways

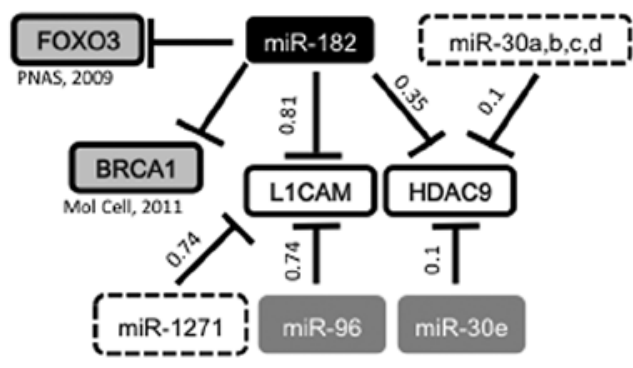

C Cytokines/Chemokines Pathways

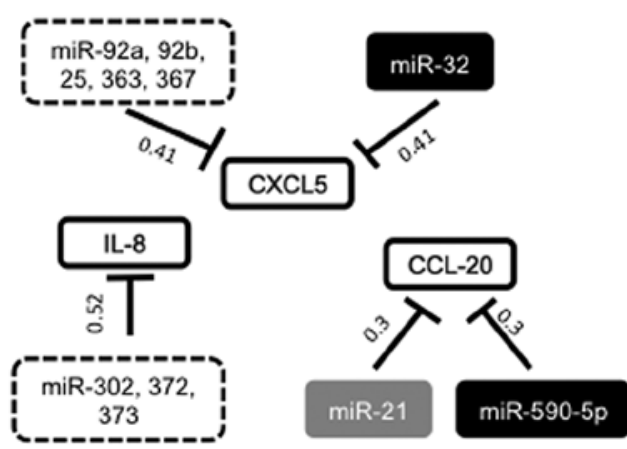

B miR-101 Pathways

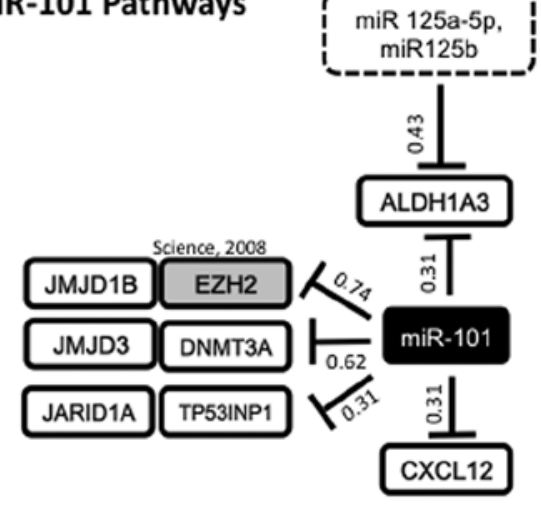

D Growth Factors/

Receptors Pathways

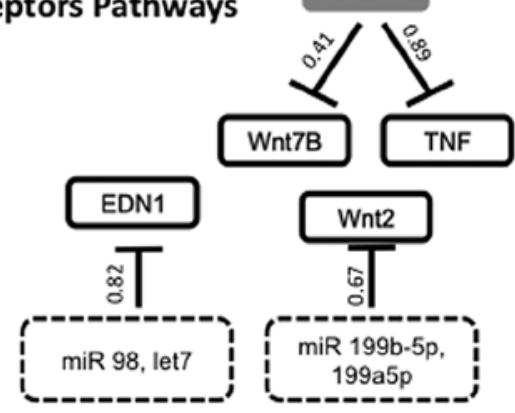

Figure 4. Summary of identified networks. The present study identified several networks, i.e., (A) miR-182 pathways, (B) miR-101 pathways, (C) cytokine/ chemokine pathways and (D) growth factors and their receptor pathways. Closed characters in black (mir-101, mir-182, miR-32 and miR-590-5p) indicate identified and verified molecules in this study, whereas closed characters in gray (miR-96, miR-30e, miR21, miR019a) show molecules of which significance was already suggested in previous studies $(3,25)$. Closed characters by dashed lines indicate molecules that were not verified in this study as linked to $\mathrm{CD}^{-} 3^{+} / \mathrm{CD}^{-} 0^{-}$ dormancy. As target mRNAs, closed characters in gray (FOXO3, BRCA1 and EZH2, and miR-182) indicate identified and verified molecules in this study and already reported as significant in previous publications, whereas open characters in bold (LICAM, HDAC9, JMJD1B, JMJD3, DNMT3A, JARID1A, TP32INP1, ALDH1A3, CXCL12, CXCL5, IL-8, CCL-20, Wnt7B, TNF, EDN1 and Wnt2) denote novel unpublished molecules identified and verified in this study.

$\mathrm{CD}^{+} 3^{+}$CD90 ${ }^{-}$cells, but not in others (Fig. 3; summarized in Fig. 3). Through this study, we were able to find at least three core regulatory networks for the maintenance of dormant $\mathrm{CD} 13^{+} / \mathrm{CD}^{-} 0^{-}$cells, but not in others, i.e., miR-182 pathways, miR-101 pathways, cytokines/chemokines pathways (IL-8, CXCL5 [http://www.genecards.org/cgi-bin/carddisp. pl?gene $=$ CXCL5\&search=CXCL5], CCL-20 [http://www. genecards.org/cgi-bin/carddisp.pl?gene $=$ CCL20\& search $=$ CCL-20]), growth factors and their receptor pathways [EDN1, Wnt2 (http://www.genecards.org/cgi-bin/carddisp. pl?gene $=$ WNT2\&search=Wnt2), Wnt7B (http://www.genecards.org/cgi-bin/carddisp.pl?gene $=$ WNT7B\&search $=$ Wnt7B), and TNF (http://www.genecards.org/cgi-bin/carddisp.pl?gene $=\mathrm{TNF} \&$ search $=\mathrm{TNF})]$. As noted in this study, we did not detect any apparent involvement in DNA damage response machineries, except for an association underlined by TP53INP1 (http://www.genecards.org/cgi-bin/carddisp. pl?gene=TP53INP1\&search =TP53INP1) and BRCA1 (http:// www.genecards.org/cgi-bin/carddisp.pl?gene=BRCA1\& search $=$ BRCA1), suggesting that (1) the damage response in $\mathrm{dCSC}$ is characteristic after exposure to genotoxic stimuli, whereas in the absence of damage insults, they are not apparent and (2) the DNA damage response was regulated mainly by the modification of proteins such as phosphorylation or ubiquitination, and the expression array technology was less sensitive to pathway detection and other networks may have been missed.

Significance of regulatory networks (Fig. 4). The EZH2 gene encodes a member of the Polycomb group (PcG) family, which forms multimeric protein complexes involved in maintaining a transcriptionally repressive state of genes over successive cellular generations (13). Reportedly, the genomic loss of miR-101, a putative tumor suppressor, leads to overexpression of histone methyltransferase EZH2 in cancer $(14,15)$, hypoxia, and androgen-dependent conditions (16) as well as in gastric cancer (17), pancreatic cancer (18), lung cancer (19) glioblastoma (20) and invasive squamous cell carcinoma (21). Thus, $\mathrm{PcG}$ proteins are critical epigenetic mediators of stem cell pluripotency and CSC functions, which may be implicated in human cancer pathogenesis, probably indicating candidacy for novel pharmacological targets of cancer therapy. Recently, it was reported that the administration of diflourinated-curcumin (CDF), a novel analogue of the turmeric spice component curcumin, has antioxidant properties and inhibits tumor growth through reduced expression of EZH2, Notch-1, CD44, EpCAM, and Nanog and increased expression of let-7, miR-26a, and miR-101 (18). These findings indicated that CDF inhibited CSC growth by targeting an EZH2-miRNA regulatory circuit for epigenetically controlled gene expression. In the present study, 
we identified various miR-101 targets, including JARID1A, JMJD1B, TP53INP1, and EZH2, suggesting that these target molecules act together to maintain CSC dormancy, and proposed the possible significance of the miR-101 pathway. We also identified the miR-182 pathway, in which miR-182-mediated downregulation of BRCA1 impacts DNA repair and sensitivity to poly-ADP ribose polymerase (PARP) inhibitors (22). The overexpression of miR-182 was reported in high-grade ovarian papillary serous carcinoma (23). Reportedly, aberrant miR-182 expression promotes melanoma metastasis by repressing FOXO3 (24). Taken together with our study, the miR-182 pathway may be involved in the maintenance of CSC function in a similar manner. As summarized in Fig. 4, we identified other cytokines, chemokines, growth factors, receptors and pathways. These findings may facilitate further studies on the regulatory mechanisms of the dormant phase of gastrointestinal CSCs.

\section{References}

1. Reya T, Morrison SJ, Clarke MF and Weissman IL: Stem cells, cancer, and cancer stem cells. Nature 414: 105-111, 2001.

2. Visvader JE and Lindeman GJ: Cancer stem cells in solid tumours: accumulating evidence and unresolved questions. Nat Rev Cancer 10: 755-768, 2008

3. Dewi DL, Ishii H, Kano Y, et al: Cancer stem cell theory in gastrointestinal malignancies: recent progress and upcoming challenges. J Gastroenterol 46: 1145-1157, 2011.

4. Li L and Clevers H: Coexistence of quiescent and active adult stem cells in mammals. Science 327: 542-545, 2010.

5. Haraguchi N, Ishii $\mathrm{H}$, Mimori $\mathrm{K}$, et al: $\mathrm{CD} 13$ is a therapeutic target in human liver cancer stem cells. J Clin Invest 120 $3326-3339,2010$

6. Sancar A, Lindsey-Boltz LA, Unsal-Kacmaz K and Linn S: Molecular mechanisms of mammalian DNA repair and the DNA damage checkpoints. Annu Rev Biochem 73: 39-85, 2004

7. Nishikawa S, Ishii H, Haraguchi N, et al: Genotoxic therapy stimulates error-prone DNA repair in dormant hepatocellular cancer stem cells. Exp Ther Med (In press).

8. Haraguchi N, Ishii H, Nagano H, Doki Y and Mori M: The future prospects and subject of the liver cancer stem cells study for the clinical application. Gastroenterology: Feb 23, 2011 (Epub ahead of print).

9. Kim HM, Haraguchi N, Ishii H, et al: Increased CD13 expression reduces reactive oxygen species, promoting survival of liver cancer stem cells via an epithelial-mesenchymal transition-like phenomenon. Ann Surg Oncol: Aug 31, 2011 (Epub ahead of print).
10. Yang ZF, Ho DW, Ng MN, et al: Significance of CD90 $0^{+}$cancer stem cells in human liver cancer. Cancer Cell 13: 153-166, 2008.

11. Weinstock DM, Richardson CA, Elliott B and Jasin M: Modeling oncogenic translocations: distinct roles for double-strand break repair pathways in translocation formation in mammalian cells. DNA Repair (Amst) 5: 1065-1074, 2006.

12. Ishii H, Iwatsuki M, Ieta $K$, Ohta D, Haraguchi N, Mimori K and Mori M: Cancer stem cells and chemoradiation resistance. Cancer Sci 99: 1871-1877, 2008.

13. Chen H, Rossier C and Antonarakis SE: Cloning of a human homolog of the Drosophila enhancer of zeste gene (EZH2) that maps to chromosome 21q22.2. Genomics 38: 30-37, 1996.

14. Varambally S, Cao Q, Mani RS, et al: Genomic loss of microRNA-101 leads to overexpression of histone methyltransferase EZH2 in cancer. Science 322: 1695-1699, 2008.

15. Friedman JM, Liang G, Liu CC, et al: The putative tumor suppressor microRNA-101 modulates the cancer epigenome by repressing the polycomb group protein EZH2. Cancer Res 69: 2623-2629, 2009

16. Cao P, Deng Z, Wan M, Huang W, et al: MicroRNA-101 negatively regulates Ezh2 and its expression is modulated by androgen receptor and HIF-1alpha/HIF-1beta. Mol Cancer 9: 108,2010

17. Wang HJ, Ruan HJ, He XJ, et al: MicroRNA-101 is downregulated in gastric cancer and involved in cell migration and invasion. Eur J Cancer 46: 2295-2303, 2010.

18. Bao B, Ali S, Banerjee S, Wang Z, et al: Curcumin analogue CDF inhibits pancreatic tumor growth by switching on suppressor microRNAs and attenuating EZH2 expression. Cancer Res 72: 335-345, 2012.

19. Zhang JG, Guo JF, Liu DL, Liu Q and Wang JJ: MicroRNA101 exerts tumor-suppressive functions in non-small cell lung cancer through directly targeting enhancer of zeste homolog 2 . J Thorac Oncol 6: 671-678, 2011.

20. Smits M, Nilsson J, Mir SE, et al: miR-101 is down-regulated in glioblastoma resulting in EZH2-induced proliferation, migration, and angiogenesis. Oncotarget 1: 710-720, 2010.

21. Banerjee R, Mani RS, Russo N, et al: The tumor suppressor gene rap1GAP is silenced by miR-101-mediated EZH2 overexpression in invasive squamous cell carcinoma. Oncogene 30: 4339-4349, 2011.

22. Moskwa P, Buffa FM, Pan Y, et al: miR-182-mediated downregulation of BRCA1 impacts DNA repair and sensitivity to PARP inhibitors. Mol Cell 41: 210-220, 2011.

23. Liu Z, Liu J, Segura MF, et al: MiR182 overexpression in tumorigenesis of high-grade ovarian papillary serous carcinoma. J Pathol: Feb 9, 2012 (Epub ahead of print).

24. Segura MF, Hanniford D, Menendez S, et al: Aberrant miR-182 expression promotes melanoma metastasis by repressing FOXO3 and microphthalmia-associated transcription factor. Proc Natl Acad Sci USA 106: 1814-1819, 2009.

25. Dewi DL, Ishii H, Haraguchi N, et al: Reprogramming of gastrointestinal cancer cells. Cancer Sci 103: 393-399, 2012. 